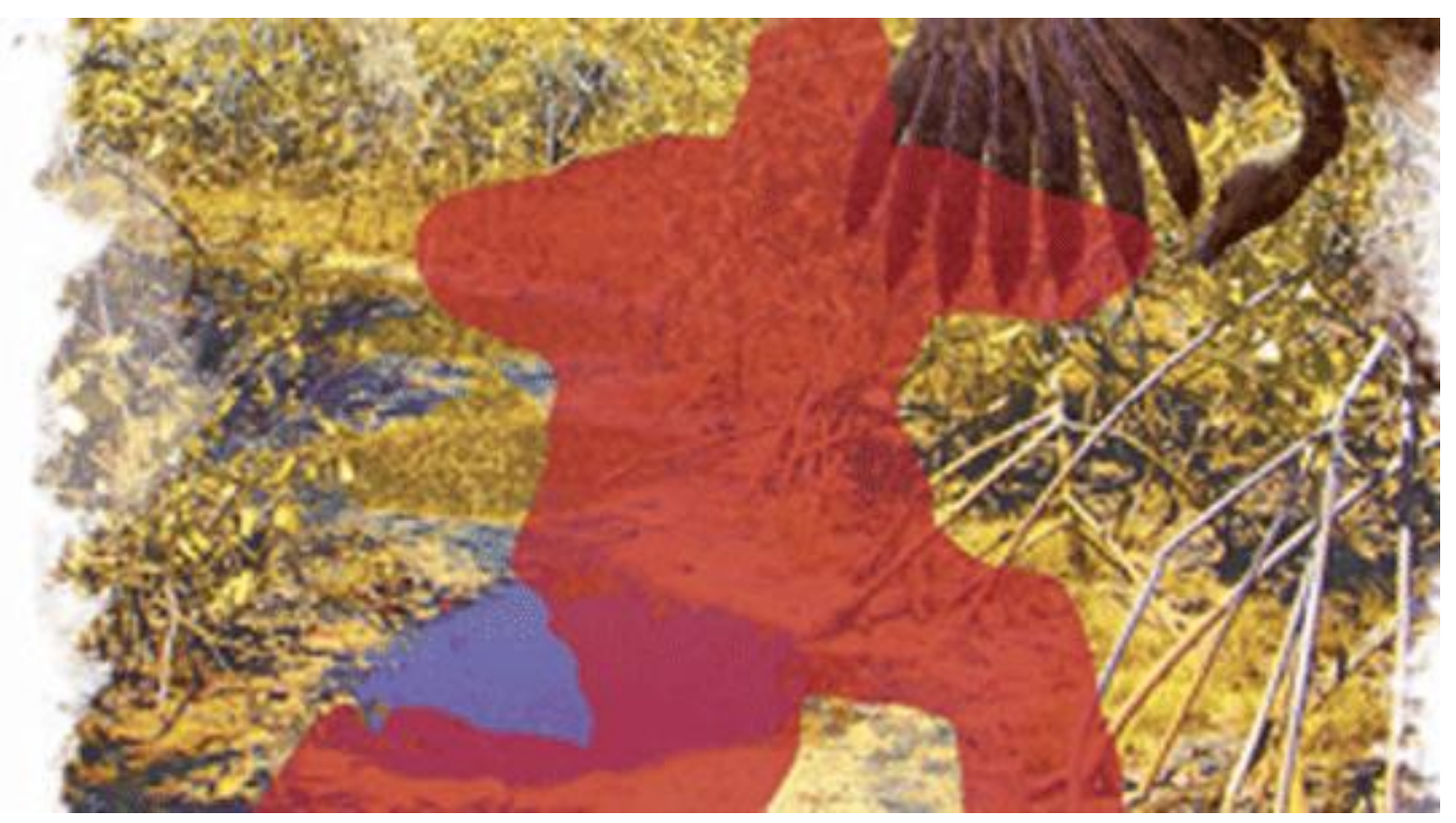

\title{
Você gosta de livro? Você é um intelectuário? Você é uma traça? Então aqui não tem nada da sua conta.
}

(Do you like books? Are you an intellectual? Are you a bookworm? Then, that's not your business anyway)

\section{Luisa Dias Brito ${ }^{1}$}

\section{Resumo}

Pensar a leitura do mundo por entre a literatura, os filmes e outras produções artísticas. Olhar/sentir/viver lugares conhecidos e desconhecidos. Estranhar o familiar. Dialogar por entre pensamentos acadêmicos e imagens: quais as possibilidades de problematizações dos padrões hegemônicos da relação sociedadenatureza que são abertas com as produções culturais?

Palavras-chave: educação ambiental; leitura; arte.

\begin{abstract}
Search for relationships between the literature movies, and the artistic productions. Look at /feel/ experience known and unknown places. Make the familiar strange. Hold talks through academic thoughts, images, and literary productions: what is the probability of casting doubt on the hegemonic patterns of the society/nature relationship which are disclosed due to cultural productions?

Keywords: environmental education; reading; art.
\end{abstract}

\footnotetext{
${ }^{1}$ Professora doutora da Universidade Estadual de Santa Cruz (Uesc), Ilhéus/BA, junto ao Departamento de Ciências Biológicas (Área de Ensino de Biologia). Endereço postal: UNIVERSIDADE ESTADUAL DE SANTA CRUZ, Campus Soane Nazaré de Andrade, Departamento de Ciências Biológicas (DCB). Rodovia Ilhéus-Itabuna, Km 16. CEP 45662-900. Ilhéus-Bahia. E-mail: luisadbrito@ hotmail.com
} 


\section{Você gosta de livro?"}

Então escrever é o modo de quem tem a palavra como isca: a palavra pescando o que não é palavra. Quando essa não-palavra - a entrelinha

- morde a isca, alguma coisa se escreveu. Uma vez que se pescou a entrelinha, poder-se-ia com alívio jogar a palavra fora. Mas aí cessa a analogia: a não-palavra, ao morder a isca, incorporou-a. O que salva então é escrever distraidamente. (LISPECTOR, 2004, p. 181)

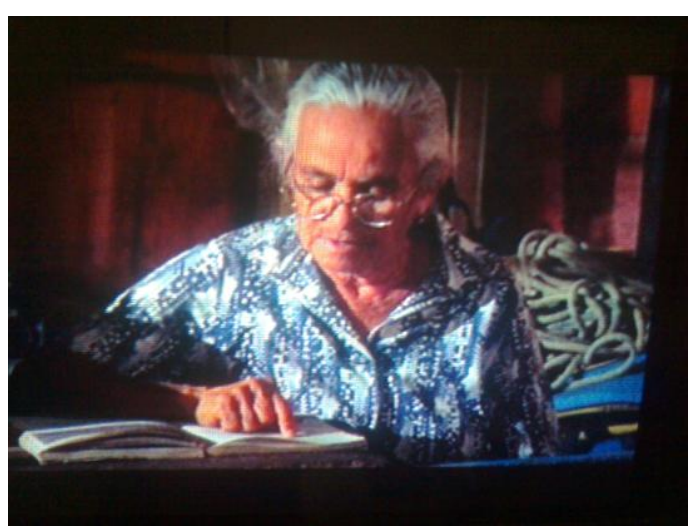

Frame congelado do filme Narradores de Javé, 2003, Eliane Caffé

O que salva então é ler
distraidamente...
ensinar distraidamente... O que salva então é aprender distraidamente...

- Ô, ô, mãe! O coco do moço mãe! Fecha esse livro, mãe! Depois de velha resolveu aprender a ler.

- Às vezes, é bom.

- Bom pra que, Zaqueu!?

- A gente nunca sabe, né? Eu mesmo que não sou das letra posso contar um rebuliço que uma escritura foi capaz de fazer. Ó, foi um caos. O caos mais, mais... Cês nem vão querer ouvir. ${ }^{2}$

\footnotetext{
${ }^{2}$ Tanto o título deste artigo, quanto esse diálogo, foram extraídos do filme Narradores de Javé (2003).
} 
Os dedos correm no papel enquanto os lábios murmuram o escrito. Os olhos estão fixos nas palavras. A mãe está esquecida dentro do livro.

O que pode acontecer quando nos esquecemos, nos perdemos dentro de um livro, de uma imagem, de uma música, de um filme, dentro de histórias e de escritas?

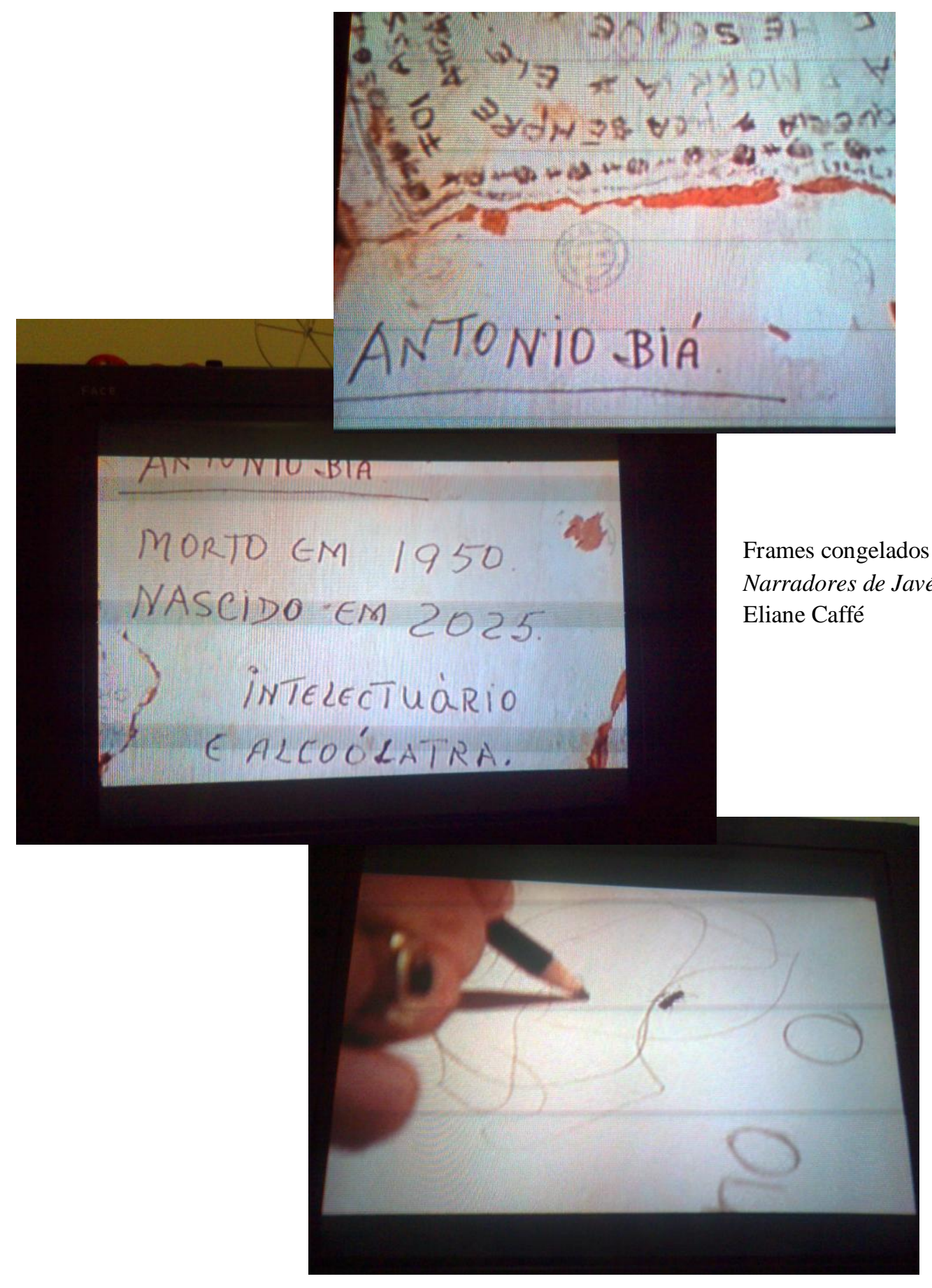

Antônio Biá, nascido em 2025 e morto em 1950, intelectuário e alcoólatra, também se perdeu dentro de histórias e escritas. Em suas mãos estiveram depositadas as esperanças para salvar o Vale de Javé. Reunir as "lembranças Javélicas”, as "históricas 
e as pré-históricas". Construir a grande "Odisséia do Vale do Javé. - Botar na escrita. Fazer um juntado de tudo que é importante pra provar para as autoridades porque Javé tem que ter tombamento". Construir "a história grande, de valor". Biá perdeu-se nas histórias... Indalécio, Indalício, Indaleo, Indaleo, Indaleo!!! Tantos mitos fundadores (ou seriam afundadores de Biá?). E uma formiga intrusa em meio às suas divagações javélicas vem lhe fazer companhia. Riscos-linhas-entrelinhas dançam no papel... é o possível. "E um dia elas vieram... as águas"3.

Gostaria neste texto de pensar o perder-se ao entrar em contato com como experiência (de)formativa. Experiência que estaria aberta para acessar/produzir vidas, intensidades, sensibilidades e criar para além do estabelecido, dos padrões, da norma (FOUCAULT, 1999). Experiência que nos possibilitaria inventar e reinventar o
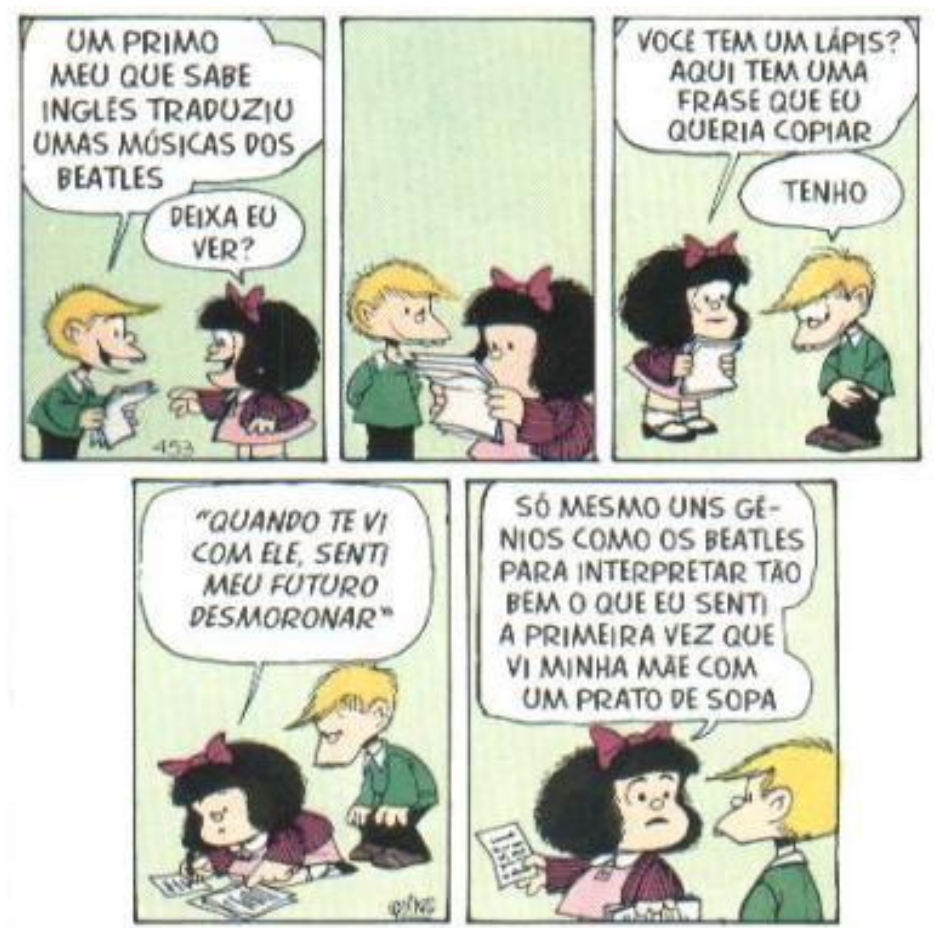

http://diversita.blog.br/testes/wpcontent/uploads/2008/11/mafalda -beatles.jpg insuspeito, proliferando pensamentos, gentes, histórias; proliferando a vida e suas formas. Viagens, perambulações, escavações, encontros inesperados. "Movimentos que regam o tempo de impossibilidades". (MALASPINA， 2011a,). Só mesmo uns gênios como os Beatles para interpretar tão bem o que eu senti a primeira vez que vi minha mãe com um prato de sopa.

Aprender está para o rato no labirinto, está para o cão que escava seu buraco, está para alguém que procura, mesmo que não saiba o que e para alguém que encontra, mesmo que seja algo que não tenha sido procurado. E, neste aspecto, a aprendizagem coloca-se para além de qualquer controle (GALLO, 2008, p.66).

\footnotetext{
${ }^{3}$ Os trechos entre aspas são diálogos de Narradores de Javé (2003).
} 
Por vezes, os movimentos são pequenos, os deslocamentos são quase imperceptíveis, mas, nem por isso, menos potentes: "é aquele momento em que você diz a si mesmo entre um suspiro e outro "nunca esquecerei esse momento". Nessa pausa é possível lamber a vida e seus sulcos de claridade que antecedem tal fala e pensamento (...)" (MALASPINA, 2011b). Como colocar em palavras essas pequenas, quase imperceptíveis, revoluções pelas quais se passa ao entrar em contato com uma obra, mas que nos transforma por completo? Não é mais possível pensar/sentir do mesmo jeito, a realidade não é mais a mesma: tecem-se outras possibilidades de ser e de existir. "De tal maneira tudo na sua boca ficava bonito, transmudado em brilho, pérola de água em folha de taioba. Seu Donga parece que come lagarta e arrota borboleta, um mais imaginoso dizia" (DOURADO, 2000, p.8)

\section{"Você é um intelectuário?"}

Vale do Javé, povo Javélico, histórias contadas e recontadas. "E um dia elas vieram... as águas”. Águas que varrem, que correm, que produzem lembranças, e lavam esquecimentos. $\mathrm{O}$ progresso engole as terras adquiridas nas divisas cantadas. As águas afogam a terra apalavrada. A energia elétrica se faz necessária.

- Os engenheiros abriram os mapas na nossa frente e explicaram tudinho nos pormenor. Tudo com os número, os fato, um tantão deles! E explicaram pra gente os ganho e os progresso que a usina vai trazer. Vão ter que sacrificar uns tantos pra beneficiar a maioria. A maioria eu não sei quem são, mas nóis é que somos os tanto do sacrifício, né não, Zaqueu?

- Os homens disseram que só não inundam quando a cidade tem alguma coisa importante, história grande. Quando é coisa de tombamento, e aí vira patrimônio. Aí ele não mexe nela.

- Ih, porra! Então, danou-se! Esse lugar velho não vale o que o gato enterra. ${ }^{4}$

Enredada e acompanhada pelos habitantes dessa terra longínqua, convido o leitor para, junto a outras obras, viajar, perambular e escavar possibilidades para (re)pensarmos a condição de ser humano e as relações estabelecidas com a natureza.

\footnotetext{
${ }^{4}$ Diálogo extraído do filme Narradores de Javé (2003).
} 


\section{$\begin{array}{llllllll}N & a & t & u & r & e & z & a . .\end{array}$}

\section{O Guardador de Rebanhos}

\section{XLVII}

Num dia excessivamente nítido,

Dia em que dava a vontade de ter trabalhado muito Para nele não trabalhar nada,

Entrevi, como uma estrada por entre as árvores, O que talvez seja o Grande Segredo,

Aquele Grande Mistério de que os poetas falsos falam.

Vi que não há Natureza,

Que Natureza não existe,

Que há montes, vales, planícies,

Que há árvores, flores, ervas,

Que há rios e pedras,

Mas que não há um todo a que isso pertença,

Que um conjunto real e verdadeiro

É uma doença das nossas ideias.

A Natureza é partes sem um todo.

Isto é talvez o tal mistério de que falam.

Foi isto o que sem pensar nem parar,

Acertei que devia ser a verdade

Que todos andam a achar e que não acham,

E que só eu, porque a não fui achar, achei.

(CAEIRO, 2001, p.86)

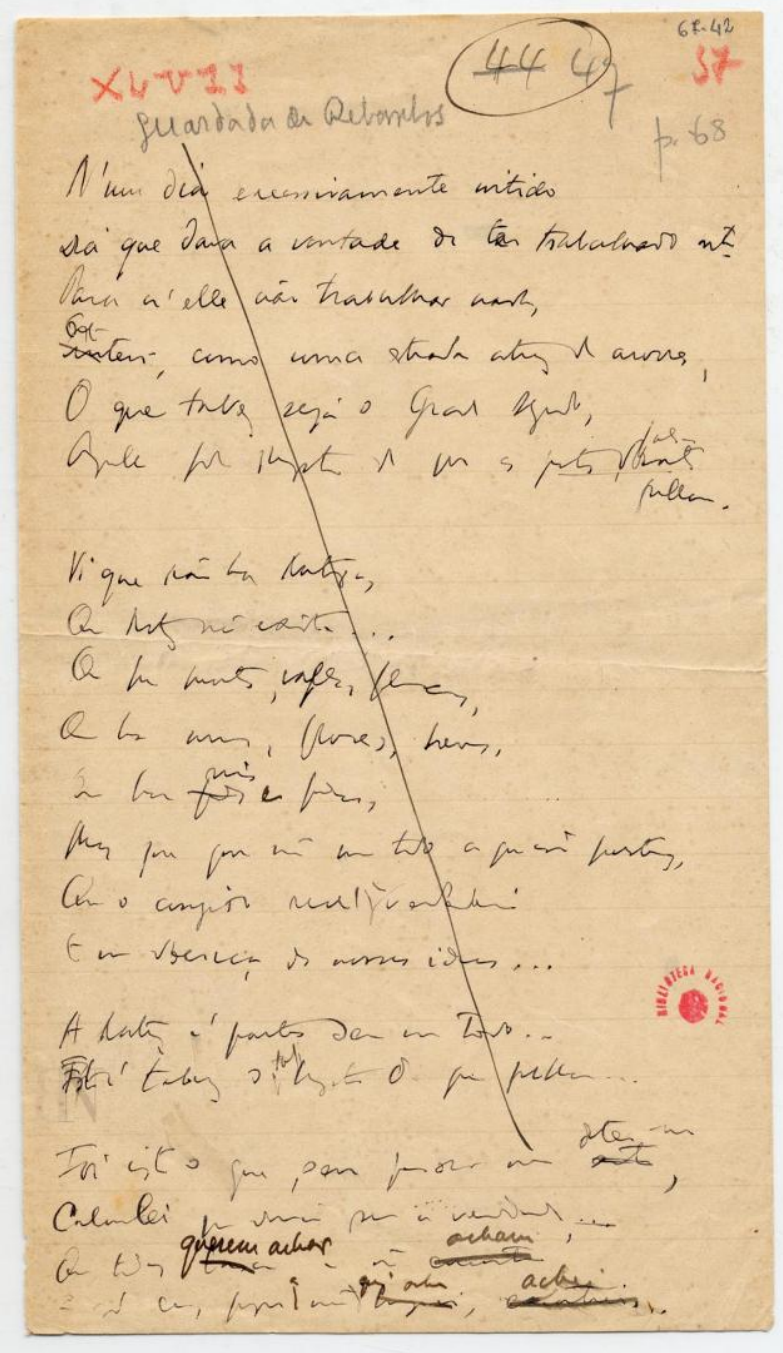

Imagem disponível em: http://purl.pt/1000/1/albertocaeiro/obras/bn-acpc-e-e3/bn-acpc-e-

e.3 item 190/P1.html

Biólogos, educadores ambientais, filósofos, e tantas outras gentes, buscam definições para natureza e discutem quais seriam as mais interessantes para determinados contextos. Aqui trarei apenas uma dessas definições, pela beleza e potência que nela estão presentes. Adauto Novaes (2003, p. 9), no capítulo de abertura do livro $O$ homem-máquina, intitulado "A ciência no corpo", traz as ideias do filósofo Merleau-Ponty que compreende existir natureza

em todos os lugares em que existe uma vida que tem um sentido mas onde, entretanto, não há pensamento [...] É natureza o que tem um sentido, sem que esse sentido tenha sido posto pelo pensamento. É a autoprodução de um sentido. A natureza é, pois, diferente de uma simples coisa; ela tem um interior, determina-se a partir do dentro, daí a oposição entre o "natural" e o "acidental" [...] É natureza o primordial, isto é, o não-construído, o não-instituído [...] A natureza é 
um objeto enigmático, um objeto que não é inteiramente objeto; ela não está inteiramente diante de nós. Ela é o nosso solo, não o que está diante, mas o que nos traz.

Que possibilidades se abrem com esse pensamento? Que torções esse pensamento provoca nas nossas formas de viver? De que maneira nós temos nos relacionado com essa natureza que nos traz?

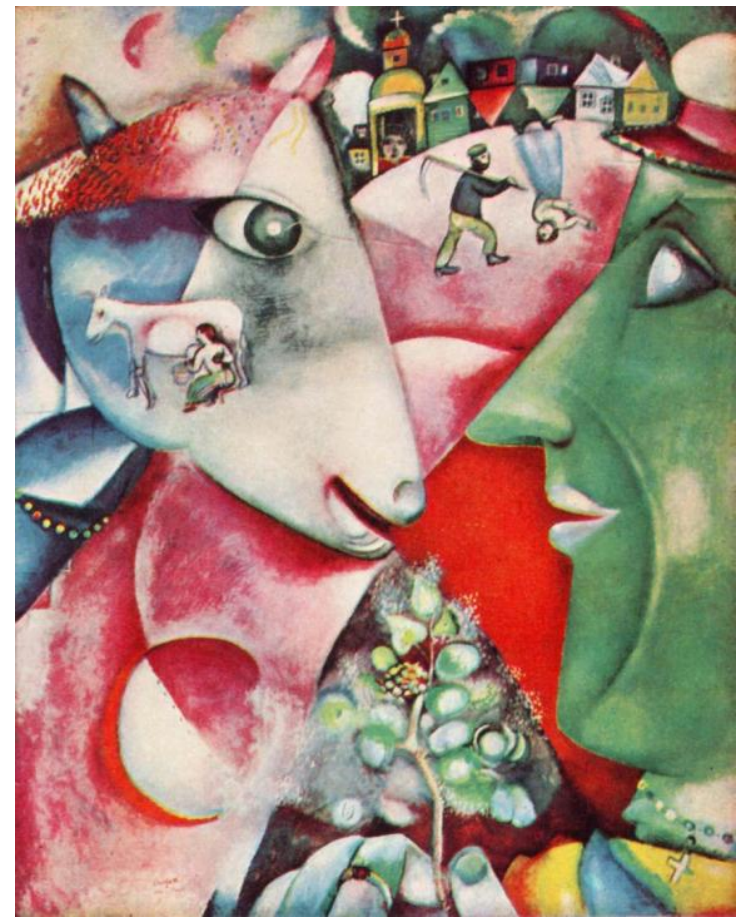

Eu e a Aldeia (1911).

Marc Chagall.

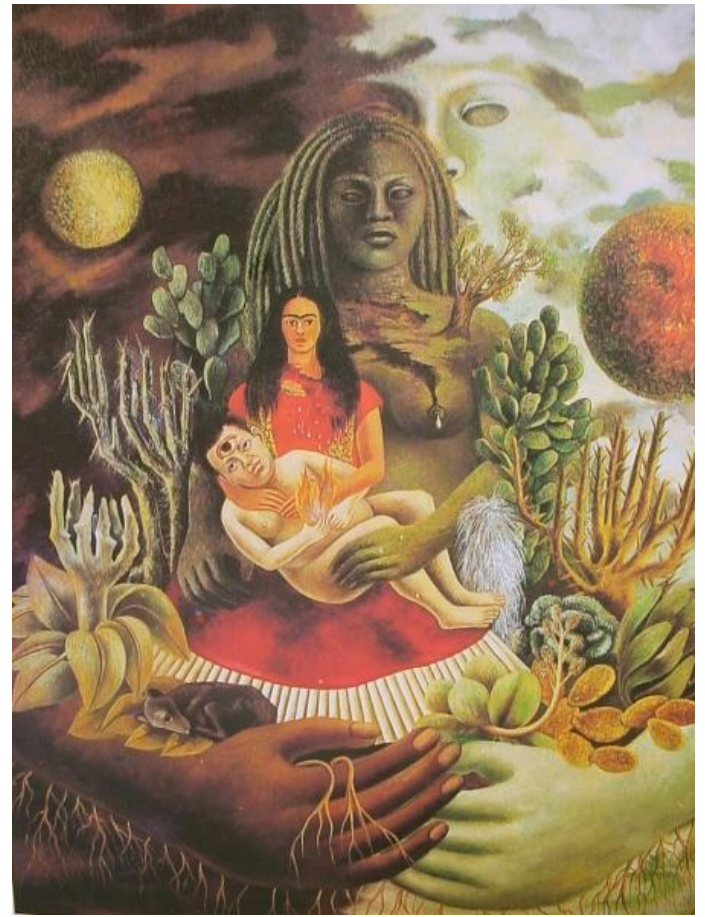

O Abraço Amoroso entre o Universo, a Terra (México), Eu, o Diego e o Señor Xólotl (1949). Frida Kahlo.

Tereza olha para elas com ternura e pensa (é uma ideia que a assalta irresistivelmente de dois anos para cá) que a humanidade é um parasita da vaca, tal como a tênia é um parasita do homem: está presa às suas tetas como uma sanguessuga. $\mathrm{O}$ homem é um parasita da vaca - seria certamente a definição que a zoologia de um não-homem daria do homem (KUNDERA, 2011).

Tereza, Frida, Chagal, Antônio Biá, Kundera, Karenine, Autran, Zaqueu, vacas, homens, mulheres, montes, vales, planícies, árvores, flores, ervas, rios, pedras, Pessoa(s)... Fios que costuram vidas. Constelações produzidas imersas em dores, feridas, alegrias, ternuras, cuidados, raiva, sangue, crueldade. Constelações pulsantes. "Isso de querer ser exatamente aquilo que a gente é ainda vai nos levar além" 
(LEMINSKI, 2011). (Des)caminhos que nos fazem pensar/viver/sentir outras naturezas, outras relações com os seres viventes e não viventes.

\section{"Você é uma traça? Então aqui não tem nada da sua conta."}

Seria possível pensar na relação sociedade-natureza sem pensar nesse caldo efervescente que traz o ser humano, que faz a vida? Que caminhos inventar para pensar/sentir/viver o não estabelecido? Como buscá-los habitando a incoerência, a contradição, o paradoxo, a não linearidade, a não dicotomização?

A proposta aqui apresentada aposta na leitura como uma possível resposta para as perguntas anteriores. Mas não qualquer leitura: nem a leitura como passatempo, mecanismo de evasão do mundo real e do eu real, nem a leitura enquanto meio de conseguir conhecimentos (já que essa "tampouco nos afeta, dado que aquilo que sabemos se mantém exterior a nós") (LARROSA, 2002, p.134).

Gostaria de pensar a leitura como formação e a formação como leitura. Pensar a "leitura como formação supõe cancelar essa fronteira entre o que sabemos e o que somos, entre o que passa (e que podemos conhecer) e o que nos passa (como algo a que devemos atribuir um sentido em relação a nós mesmos”). (LARROSA, 2002, p.136. grifos do autor.). E pensar a formação como leitura diz respeito à relação de produção de sentido que damos àquilo com o qual nos encontramos.

É como se os livros, assim como as pessoas, os objetos, as obras de arte, a natureza, ou os acontecimentos que sucedem ao nosso redor quisessem nos dizer alguma coisa. E a formação implica, necessariamente, nossa capacidade de escutar (ou de ler) isso que essas coisas têm a nos dizer. Uma pessoa que não é capaz de se pôr à escuta cancelou seu potencial de formação e de trans-formação (LARROSA, 2002, p.137).

As produções culturais dão a conhecer as crises ambientais a partir de lugares os mais variados, colocando em relação uma série de questões humanas que constituem formas tanto de habitar os mais diversos espaços, quanto de convivência entre os seres. Com elas abre-se a possibilidade de pensar e repensar o mundo a partir de perguntas, sentidos, sensações, linguagens, tensões, intenções, sonhos, desejos que o constituem.

Viver a leitura como formação e a formação como leitura pode abrir caminhos para a (trans)formação. E como o tal rato no labirinto e o cão cavando seus buracos, vamos encontrando o que não havíamos procurado; achamo-nos e nos perdemos. E esse é o encantamento. É a viagem que nos forma e nos transforma. “- Ô, ô, mãe! O coco do moço mãe! Fecha esse livro, mãe! Depois de velha resolveu aprender a ler”. 
O Projeto "Olhares Cotidianos da Certificação Turismo Carbono Neutro: logos e grafias de uma transformação na APA Itacaré-Serra Grande/BA" ${ }^{\text {, }}$, desenvolvido pela equipe de professores, técnicos e artistas da Instituição Movimento Mecenas da Vida e da Universidade Estadual de Feira de Santana (Uefs), aposta na possibilidade do encontro com a fotografia para potencializar a busca de caminhos para pensar as questões socioambientais presentes e vivenciados pelas pessoas (os membros das famílias dos agricultores tradicionais, os empresários, a comunidade local e os turistas) que habitam aquela localidade.

A partir dos olhares cotidianos dos protagonistas (agricultores, esposas e filhos, assim como os empresários certificados) propõe-se uma inovação na avaliação desta tecnologia uma vez que serão eles mesmos que expressarão o que é a Certificação Turismo $\mathrm{CO}_{2}$ Neutro e as transformações construídas/conquistadas em suas vidas. Conhecimentos e vozes em fotografias que não serão fonte de pesquisa e ou análise no que diz respeito a serem traduzidas ou interpretadas, mas com elas, as imagens, produzir, compartilhar e inventar expressões dos conhecimentos, das relações entre os seres humanos e o ambiente em que vive (ANDRADE et al, 2010, p.5).

Nesse projeto, a relação com a fotografia deixa de ser aquela da representação e passa a ser a da criação de sentidos e de escuta. Uma vontade de aberturas de caminhos para uma (trans)formação, apostando na leitura como formação e na formação como leitura. O que será que dizem as fotografias aos agricultores e suas famílias? Que relações de escuta são estabelecidas? O grupo de executores do projeto acredita que a potência do trabalho com as fotografias está na abertura para o "poemar o cotidiano": "poesia também como forma de registro e possibilidades de avaliação de práticas do dia a dia, de despertar o político na expressão dos saberes, sejam quais forem os sujeitos/praticantes/produtores desses conhecimentos" (ANDRADE et al, 2010, p.8).

Porque a arte foge às determinações pré-estabelecidas e, ao mesmo tempo, nos impele a decifração dos signos que faz brotar os sentidos, libertando singularidades de vida, de gente, de lugares, de almas perdidas a sonharem... (ANDRADE; FARIA, 2010, p. 14)

... a florescerem...

\footnotetext{
${ }^{5}$ Edital n015/2009 “Apoio a Tecnologias para o Desenvolvimento Social” da Fapesb.
} 
Arte, cinema, literatura. Encontrar-se com... Perder-se... As imagens e as escritas aqui trazidas me fazem pensar que o político está no imbricamento do mais pessoal com o entorno; é no mais cotidiano que ele se tece, nas relações de força e de intensidades. As fronteiras entre as dimensões consideradas do mundo privado, menores, pequenas, subjetivas, pessoais, e aquelas chamadas do mundo público, sociais, políticas, econômicas, podem se liquefazer. Leitura como formação e formação como leitura que nos coloca em contato com naturezas múltiplas, construindo possibilidades de existência e de vida nessa imensa (ou pequena, tudo depende do ponto de vista) coisa que chamamos planeta Terra.

\section{Referências Bibliográficas}

ANDRADE, E. C. P.; BRITO, L.; Pinto Filho, J. B.; Arbat Bau, E. Olhares cotidianos entrelaçando saberes, culturas, bio-logias através da fotografia. Revista da SBEnBIO, v. 3, p. 2467-2476, 2010.

ANDRADE, E. C. P.; FARIA, M. C. T. Arte dos problemas e/ou problemar(-)te. In: IV Colóquio Internacional Educação e Contemporaneidade, 2010, Aracaju. IV Colóquio Internacional Educação e Contemporaneidade, 2010. v. 1. p. 1-14.

CAEIRO, A. Poesia: São Paulo: Companhia das Letras, 2001.

DOURADO, A. Novelário de Donga Novais. Rio de Janeiro: Rocco, 2000.

FOUCAULT, M. Aula de 17 de março de 1976. In: Em defesa da sociedade: curso no Collège de France (1975-1976). São Paulo: Martins Fontes, 1999. p. 285315.

GALLO, S. Deleuze e a educação. 2ed. Belo Horizonte: Autêntica, 2008.

KUNDERA, M. A insustentável leveza do ser. Disponível em: $<$ http://katalivros.com/downlods.asp?detalhe1=950>. Acesso em: 10/05/2011.

LARROSA, J. Leitura, experiência e formação. In: COSTA, M. V. Caminhos investigativos: novos olhares na pesquisa em educação. Rio de Janeiro: DP\&A, 2002. p. 133-160.

LEMINSKI, P. Disponível em: <http://www.releituras.com/pleminski_menu.asp>. Acesso em: 10/05/2011.

LISPECTOR, C. Aprendendo a viver. Rio de Janeiro: Rocco, 2004.

MALASPINA, T. Sem título. Disponível em <http://infinitonulo.blogspot.com/>. Acesso em: 10/05/2011a. 
Você gosta de livro? Você é um intelectuário? Você é uma traça? Então aqui não tem nada da sua conta.

Sobre o Infinito Nulo. Disponível em:

$<$ http://manazinabre.blogspot.com/search?updated-max=2009-03-

13T08\%3A52\%3A00-03\%3A00\&max-results=7>. Acesso em 10/05/2011b.

NOVAES, A. A ciência no corpo. In: . (org.). O homem-máquina: a ciência manipula o corpo. São Paulo: Companhia das Letras, 2003. p. 7-14.

\section{Filmografia}

Narradores de Javé (2003), dirigido por Eliane Caffé, Brasil. 


\section{Para citar essa obra:}

BRITO, Luisa Dias. Você gosta de livro? Você é um intelectuário? Você é uma traça? Então aqui não tem nada da sua conta. RUA [online]. 2011, no. 17. Volume 1 - ISSN 1413-2109

Consultada no Portal Labeurb - Revista do Laboratório de Estudos Urbanos do Núcleo de Desenvolvimento da Criatividade http://www.labeurb.unicamp.br/rua/

Laboratório de Estudos Urbanos - LABEURB

Núcleo de Desenvolvimento da Criatividade - NUDECRI

Universidade Estadual de Campinas - UNICAMP

http://www.labeurb.unicamp.br/

Endereço:

Rua Caio Graco Prado, 70

Cidade Universitária "Zeferino Vaz" - Barão Geraldo

13083-892 - Campinas-SP - Brasil

Telefone/Fax: (+55 19) 3521-7900

Contato: http://www.labeurb.unicamp.br/contato 